\title{
PRESENCIA DE NAVARROS Y VASCOS EN LA REPOBLACIÓN DE MURCIA
}

\author{
Ángeles GARCÍA DE LA BORBOLLA
}

Departamento de Historia. Universidad de Navarra

La victoria de las Navas de Tolosa implicó de manera directa a todos los reinos peninsulares en la lucha contra el Islam. A partir de este momento, los castellanos enfocan su área de actuación hacia el fértil valle del Guadalquivir, teniendo como apéndices de sus conquistas hacia el oeste el reino de Niebla y hacia el este el Reino de Murcia. Mientras tanto el monarca aragonés centrará sus esfuerzos reconquistadores en la zona levantina.

Por su parte Sancho el Fuerte, a quien vemos combatiendo en 1212 en las estribaciones montañosas de Sierra Morena, reorientrá su política exterior hacia lo que era la gran empresa plenomedieval y el espíritu que imbuía a todos estos hombres: la recuperación de los territorios en manos de los infieles. Para ello y a pesar de que Navarra no contaba con zonas limítrofes con Al-Andalus, pero si con una sólida base económica que le permitirá hacerse con territorios en la Frontera (ej. comarca de Linares, 1213).

La actividad que en un primer momento impulsó este monarca navarro se vería acompañada por un proceso paralelo de despliegue demográfico y social que desborda los límites geográficos de estas regiones y que desde la Rioja y siguiendo la vertebración del Sistema Ibérico, se dirige hacia el Levante.

\section{LA DOMINACIÓN POLÍTICO-MILITAR: LA CONQUISTA}

La incorporación del reino de Murcia a la corona castellana no se inicia con una campaña militar sino con un compromiso firmado en la villa de Alcaraz en abril de 1243. A partir de ese momento gran parte del reino murciano entra en un régimen de protectorado, reconociendo a su hasta ahora enemigo más poderosos y cercano, 
Castilla, la soberanía así como la tenencia de las principales fortalezas que le permitiera garantizar la defensa del territorio y la concesión de la mitad de las rentas públicas. Por otra parte, la población autóctona conservaría no sólo sus costumbres y tradiciones sino también su gobierno y religión.

Desde la muerte de lbn Hud, protagonista de la sublevación frente al poder almohade de la Península, se suceden una serie de gobiernos inestables bajo un clima de anarquía y fragmentación política. El fracaso de las tentativas de Muhammad lbn Hud por lograr una nueva reunificación del reino, así como las amenazas por una parte del reino vecino de Granada, donde Al-Ahmar acababa de tomar Almería, y por otra de la avanzada hacia el sur del monarca aragonés Jaime I, conquistador de Valencia, llevan al emir murciano, que no contaba con fuerzas militares suficientes que le garantizasen su protección, a buscarla en el exterior. Y será Castilla, la que presentaba condiciones más idóneas. Suponiendo al mismo tiempo para el reino de Fernando III la toma de un territorio sin necesidad de desgaste militar.

Sin embargo, el tratado por el cual se entregaban según cuenta la Crónica General la cibdad de Murcia e todos los castillos que son desde Alicante fasta Lorca e fasta Chinchilla no fue signado por todos los arraeces del reino: Lorca, Mula y Cartagena no aceptan esta pleitesía ${ }^{2}$, así como Orihuela, Elche, Alicante, Aledo y Ricote. Esto suponía un grave obstáculo para la incorporación pacífica del reino que al menos exigía el dominio de las plazas principales. De este modo, a partir de la firma del tratado de Alcaraz se inicia un periodo en el que el dominio castellano se fue extendiendo por estas tierras bajo condiciones muy diferentes: Mula y Cartagena acaban rindiéndose a las huestes alfonsíes bajo ninguna condición y con la consiguiente expulsión de su población ${ }^{3}$; Lorca, tras un largo asedio y con la muerte de su gobernador, capitula y acepta el pacto, como también lo hacen Orihuela y Alicante una vez son tomadas por las armas.

Tras estas campañas dirigidas por el infante castellano y que finalizan en 1257, era necesario el afianzamiento del dominio sobre estas nuevas tierras, que como a lo largo de años anteriores quedaba garantizado emprendiendo una labor de repoblación del territorio.

El ideario político de Alfonso iba dirigido a conseguir un doble objetivo: la paz y seguridad en las zonas reconquistadas. Situación que se puso gravemente en entredicho hacia 1264, año de la sublevación mudéjar en Al-Andalus, que aunque fracasó desde un primer momento en Lorca y Orihuela no fue así en Murcia. Este episodio ocasionará la intervención militar del monarca aragonés, suegro de Alfonso, en el solar

1 J. TORRES FONTES, La Reconquista de Murcia en 1266 por Jaime I de Aragón. Murcia, 1967.

2 Et dessta guisa apoderaron los moros al infante don Alfonso, en boz del rey don Fernando su padre en todo el reyno de Murçia, ssaluo Lorca et Cartagena et Mula que no quisieron dar ni entrar en la pleitesia que los otros: et ganaron y poco ca a la çima ouieronlo a Jazer mal SU grado (ed. R. MENÉNDEZ PIDAL Primera Crónica General de España. Madrid 1955. n² 1.060. Esta obra se citará CGE).

3 Et corrio Mula et Lorca et Cartagena et esos logares rebeldes que se le non querien dar et tirolas et astragolas todas...et el infante don Alffonso echo todos los moros ende. CGE $n^{0} 1.065$. 
murciano. Las fuerzas del castellano resultaban insuficientes, con lo cual se ve obligado a acudir a Jaime I, que a pesar de contar con la oposición de gran parte de la nobleza acude y somete a Murcia ${ }^{4}$ empleando sus dotes diplomáticas más que las armas. Esta participación activa en la política castellana le lleva a aconsejar al infante castellano en la entrevista que mantuvieron en Tarazona durante las Navidades de 1270: «lo que debéis de hacer es que queden en la ciudad cien hombres de valor....que vivan allí con suficiente patrimonio" nada más alejado de las ideas de Alfonso ${ }^{5}$.

\section{LA APARICIÓN DE UNA NUEVA SOCIEDAD: REPOBLACIÓN Y REPARTIMIENTOS}

La expansión militar que había permitido a las tropas castellanas, en tan sólo unos años, llegar al litoral mediterráneo, iba acompañada por una labor repobladora dirigida por los propios soberanos que se traduce en la instalación de contingentes de población cristiana llegados a estas tierras y que se presentan como elementos indispensables para su defensa, pues la repoblación de un territorio era la mejor garantía de su conservación.

Del mismo modo, esto suponía el paso de una sociedad a otra. De un mundo poblado, urbanizado y gobernado por el poder musulmán que supo forjar durante siglos una brillante civilización, a otro en el que nace una sociedad nueva que se integra con mayor o menor resistencia dentro de los reinos cristianos. Sociedad compuesta por gentes de diferentes orígenes y por tanto culturas, de diversas condiciones socio-profesionales y por tanto económicas. En definitiva este trasvase de población implicaba una restructuración social y una reorganización de tierras que impidiesen un colapso económico-social y pusiese en crisis el poder cristiano en el lugar reconquistado.

Pero Alfonso carecía de medios humanos suficientes para llevar desde el primer momento una repoblación intensiva; recordemos que de manera paralela se está produciendo la conquista y repoblación de Andalucía, lo que ocasionará una repoblación lenta y en varias fases en el territorio murciano. Todas las villas fueron objetos de sucesivos repartos de tierras, los más tardíos tienen su explicación en la conquista del reino por el aragonés Jaime II, durante la minoría de Fernando IV de Castilla. Los restantes pueden tener varias explicaciones: la movilidad inicial de los repobladores que se dirigen hacia las tierras andaluzas; la necesidad de atraer nuevos pobladores ante la emigración de los mudéjares al reino de Granada. Por ejemplo en el caso de Lorca, su carácter fronterizo obliga a trasladar población hacia la villa desde puntos muy expuestos a ataques granadinos.

Sin embargo, la tarea se presentaba urgente debido a la amenaza constante que

4 Datum in obsidione Murcie nonas januarii anno Domini MCCLX quinto (documento fechado por el afio de la Encarnación). (J. MIRET Y SANS. Itinerari de Jaume l «El Conqueridor», Barcelona, 1918 , p. 382).

5 Sobre las diferencias entre Jaime I y Alfonso $X$ en la repoblación de Murcia, vid. J. TORRES FONTES, Jaime I y Alfonso X. Dos criterios de repoblación, VII Congreso de Historia de la Corona de Aragón, Barcelona, 1962, pp. 329-340. 
ejercían sus poderosos vecinos: Granada y Aragón. Esta condición fronteriza no resultaba un factor muy atractivo para los nuevos pobladores, que al abandonar sus lugares de orígenes buscaban tierras donde asentarse que les garantizasen un medio de vida más fácil y productivo.

Según M. González Jiménez en su obra Alfonso X (1252-1284), la repoblación del reino de Murcia conoció dos fases: una primera desde 1244 a 1264, con una limitada presencia cristiana reducida a las guarniciones militares de las principales fortalezas aunque un tanto mayor en las poblaciones conquistadas militarmente. De esta primera fase destacaremos la repoblación de Cartagena (1246) y Alicante (1252), de las que no se ha conservado el texto de su repartimiento. Ambas villas, importantes baluartes defensivos dada su situación costera, capitularon y recibieron el fuero de Córdoba $^{6}$. Una segunda etapa se abre en 1266, tras ser sofocado el levantamiento de los mudéjares en Al-Andalus, y se extiende más allá del reinado de Alfonso $X$ (hasta Fernando IV y Alfonso XI).

Con la repoblación del reino de Murcia se iniciaba al mismo tiempo su castellanización, a pesar de que nos encontraremos ante una realidad que merece ser señalada, nos referimos al importante peso demográfico que supusieron catalanoaragoneses en el conjunto de nuevos pobladores llegados a estas tierras. Tomemos algunos ejemplos significativos:

J.M. Lacarra que cifró la población global de Murcia, tras todos los repartos, en 2.835 , contabilizó un total de $1.238(48 \%)$ procedentes de la corona aragonesa, siendo incluso mayor el número de catalanes, 1.108, que el de aragoneses, 105. Frente a unos 517 castellanos $(18 \%)^{7}$.

Para el caso de Orihuela, J. Torres Fontes en su artículo La procedencia de los repobladores en el repartimiento de Orihuela, "Miscelánea Medieval Murciana», 1986, Vol. XIII, establece los siguientes porcentajes sobre el origen de los pobladores que se beneficiaron de los sucesivos repartos de tierras orolianas: catalanes: $266(24,40 \%)$; aragoneses : $192(17,61 \%)$; valencianos: $48(4,40 \%)$; no peninsulares: $12(1,10 \%)$; castellanos: $238(21,83 \%)$; navarros: $70(6,42 \%)$; extranjeros $5(0,45 \%)$; indeterminados; 259 (23,76\%).

En definitiva, si políticamente Murcia pertenece al reino de Castilla es sin duda un

6 En el caso de Murcia en 1257 se realiza el primer reparto de una zona al margen del Segura, situada a unos diez kilómetros del este de su muralla, «Las Condominas», unas 450 tahúllas de 200 alfabas de valor. En Orihuela no se inician los repartimientos hasta 1264 y en Lorca se documentan concesiones de donadíos en fechas tempranas, pero su repoblación no comienza hasta 1257.

7 Estos porcentajes varían si tomamos en cuenta que el número total de pobladores es menor: entre 2.380-2.400, tal como J. TORRES FONTES expone en su obra Huerta y campo de Murcia en el siglo XIII, Murcia, 1971. Alterando del mismo modo los dados en el siglo XVIII por F. CASCALES en sus Discursos históricos.

Hacia 1272 el porcentaje de catalano-aragoneses era de $55,9 \%$ frente a $23,6 \%$ de castellanos, en un total de 1974 pobladores: 951 catalanes; 91 aragoneses; 60 valencianos; 1 mallorquín y 467 castellanos. (D. MENJOT, Murcie (1243-milieu XV siècle). Une ville mediterranéenne perisphérique dans la Castille du Bas Moyen Age. Tesis doctoral, Niza, 1990). 
reducto de pobladores de la corona de Aragón, muchos de los cuales habían formado parte de las huestes de Jaime I y para otros supuso un nuevo terreno de expansión, pues la conquista de Valencia quedaba ya muy lejos ${ }^{8}$.

La ocupación del solar fue gradual mediante sucesivos repartos minuciosos y metódicos que conocen y respetan la organización musulmana precedente ${ }^{9}$. Como en el caso andaluz se distribuyeron tierras tanto en donadíos, aunque su número es muy reducido limitándose a miembros de la familia real o nobles y que tienden a desaparecer, y en heredamientos, cuyas tierras se encontraban dispersas entre las diferentes cuadrillas con el fin de evitar la concentración de grandes propiedades en pocas manos.

Cada poblador según su categoría social, existían tres categorías de caballero y tres de peones, recibe un número de alfabas (valor en renta de las tierras) pero con diferentes extensiones o tahúllas, ya que la variedad de tierras impedía establecer un canon distributivo fijo.

\section{VASCOS Y NAVARROS EN MURCIA EN EL SIGLO XIII}

En este epígrafe nos centraremos en determinar la participación de gentes de origen navarro y vasco, a partir del estudio del libro de Repartimiento de Murcia que junto al de Lorca y Orihuela son los que se han conservado hasta nuestros días. Cuantificaremos sus porcentajes a partir del análisis sobre los nombres locativos que nos desvelan la identidad social del individuo, y que actúa de elemento diferenciador frente al otro ${ }^{10}$. De este modo el topónimo es un espacio que dota de identidad, que facilita la unión y cohesión en grupos compactos de individuos de diferentes casas pero provenientes de los mismos lugares. En una sociedad nueva, en constante situación de peligro, en tierras que resultaban desconocidas, sería una tendencia lógica y natural el reagrupamiento con aquellos identificados por el apellido como vezinos que iban llegando en sucesivas oleadas.

Sin embargo, incluso antes de que se comiencen a asentar estos emigrantes procedentes de las tierras navarras y vascas, encontramos en las fuentes la participación activa de grandes y a quien vemos participar en las campañas que realiza el infante

8 ...e poblada la tierra de los mas cristianos que podía aver e senaladamente fazia mucho para poblar de cristianos la cibdat de Murcia e la villa de Orihuela o la villa de Lorca, e porque no podía aver gentes de la su tierra que les poblasen, vinieron e poblaron muchos catalanes de los que eran venidos a poblar el reino de Valencia. (Crónica del rey Don Alfonso Décimo. Biblioteca de Autores Españoles, LX, p. 11).

9 En Murcia se efectúan cinco repartos desde su conquista hasta 1272. En Orihuela, seis particiones, cinco de las cuales son castellanas. Desde 1265 a 1314. En Lorca de 1265 a 1270, su carácter fronterizo se evidencia en su población mayoritariamente militar. Siendo sus categorías: caballero, adalid, almogávares a caballo, almocadenes, ballesteros y peón.

10 La antroponimia occidental utiliza un sistema descriptivo, que hace referencia ya sea al lugar de origen, a su filiación, a su profesión, o a sus caracteres físicos o morales que permite saber cuales son las creencias, las costumbres, los usos, la organización política, las lenguas y los trabajos de los habitantes así como sus particularidades geográficas y geológicas del país. (E. VROONEM, Anthroponymie universelle comparée. Bruselas, 1967). 
entre 1243 y 1257 en Murcia ${ }^{11}$. En estas mismas campañas encontramos documentada la presencia de otros nobles cuyos linajes son originarios de estas tierras: Don Roy López de Mendoza, noble alavés, muy ligado al infante Alfonso junto al que combate en Murcia, Mula y Lorca ${ }^{12}$.

Pero quizás debemos detenernos en esta relación de grandes personajes de origen navarro y vasco que participan tanto en las campañas militares acompañando al infante, en un personaje de gran trascendencia no sólo en la conquista sino también en los años posteriores participando en la organización del territorio murciano. Nos referimos a Don Gil García de Azagra. Su apellido hace clara referencia a su origen navarro ${ }^{13}$. Fue el más activo de los designados por Alfonso $X$ pata llevar a cabo los repartimientos de Murcia $^{14}$.

11 Don Diego participa también en la conquista de Jaén (1246) y de Sevilla (1248) donde recibirá importantes bienes. La subida al trono de Alfonso $X$ supone un cambio importante en las relaciones con esta casa nobiliaria que acaban con la desnaturalización del reino, pasando entonces al servicio del monarca aragonés. (J. GONZÁLEZ, Reinado y diplomas de Fernando III. Córdoba, 1983. T. I pp. 133-137).

12 Roy López de Mendoza es nieto de Íñigo de Mendoza, quien participó en las Navas de Tolosa. En los privilegios alfonsíes aparece nombrada como almirante mayor de la mar. F. CASCALES, embiò su flota sobre Cartagena con Rui Lopez de Mendoza su Almirante i por tierra a Don Gil García de Azagra y a Diego Lopez de Salcedo Merino mayor de Castilla Estos últimos personajes también presentan un claro origen navarro el primero y alavés el segundo. López de Mendoza fue nombrado repartidor de la vega sevillana. (J. GONZÁLEZ, El Repartimiento de Sevilla Madrid, 1951. T. I, p. 241 y T. II, p. 13) e por poblar e asosegar la noble dicha cibdad de Sevilla .

13 Azagra se localiza en las tierras de la ribera en la Navarra meridional.

El espacio geohistórico de Navarra se puede dividir en tres sectores: la "Navarra nuclear", los confines trasmontanos y las tierras nuevas y riberas. El primero se corresponde al solar originario de la monarquía pamplonesa, que abarca las cuencas y valles intrapirenáicos dispuestos en torno a la Cuenca de Pamplona. Los confines trasmontanos engloban el espacio traspirenaico y atlántico del actual territorio foral y, por último, las tierras nuevas y riberas se identifican con la amplia franja espacial dispuesta sobre las tierras exteriores de la cordillera pirenáica hasta la comarca tudelana. (J. PAVON BENITO, El poblamiento medieval navarro. Base socioeconómica del espacio monárquico. Pamplona, 1996. Tesis inédita en prensa).

14 Don Gil García de Azagra. ZURITA en su España Sagrada, XLII, 324, lo señala como uno de los ricos hombres que acompañan a Jaime I en 1225 en el sitio de Peñíscola, donde aparece como confirmante de dos documentos. Su padre combatió al lado de Jaime I el Conquistador lo cual le valió el recibir numerosas mercedes y heredades. Casado con doña Toda Ladrón que era pariente de doña Teresa Gil de Vidaurre, una de las mujeres de Jaime I, lo que explicaría su participación activa en la política aragonesa.

Tras servir hacia 1260 al rey de Aragón pasa al servicio del monarca castellano en 1263, donde entre sus episodios más destacados sería el ataque y reconquista de Cartagena en 1265 donde asumió la jefatura junto a Diego López de Salcedo. Seguidamente lo encontramos con las tropas castellanas y las aragonesas de Jaime I en la reconquista de Murcia.

Desde mayo de 1262 a mayo de 1272 aparece como confirmante de los privilegios rodados de Alfonso $X$, ocupando un lugar destacado entre los de su categoría.

Realmente fue el verdadero rector de las particiones, ya que documentamos actuaciones en las que movido por su propia voluntad incrementaba ciertos heredamientos o realizaba cambios de lugar. 


\subsection{Navarros}

En pocos años, de 1243 a 1273 se lleva a cabo un repartimiento perfectamente organizado y orientado a cubrir deficiencias, ausencias no justificadas (sobre todo a partir de la tercera partición de 1266) y a compensar a los nuevos pobladores. Es Murcia el foco principal de atracción de pobladores cristianos ansiosos por tomar posesión de ricas tierras como lo era su huerta. Sin embargo, al ser esta una repoblación coetánea a la efectuada en tierras andaluzas, pocos eran las gentes que Castilla podía ofrecer. La proximidad de reinos como el de Aragón y la reciente repoblación valenciana y mallorquina abría las puertas a gentes aragonesas, catalanas y navarras que «buscan en la aventura de la emigración las esperanzas y posibilidades que podía proporcionarles el Sureste» (J. Torres Fontes vid. nota 7).

A la hora de presentar la cuantificación exacta de pobladores que se instalan en el solar murciano encontramos divergencias numéricas entre los 21 navarros contabilizados por José María Lacarra y los 19 por Denis Menjot ${ }^{15}$ en una población total de 1.974 repobladores entre 1266 y 1272.

Sin embargo, un análisis pormenorizado de las fuentes, es decir de las sucesivas particiones que contiene el Libro de Repartimiento, permite establecer la cifra de 27 pobladores de origen navarro, como atestiguan sus apellidos toponímicos, que bien pueden indicar su origen regional o su origen geográfico preciso.

A este respecto y en relación con el primero de estos casos, nos encontramos con la presencia de siete individuos cuyo nombre va seguido del etnónimo «navarro», todos ellos beneficiados con tierras en la tercera y cuarta partición de acuerdo su con-

Su labor fue reconocida y premiada desde un primer momento por Alfonso $X$, con la concesión de un donadío que superaba incluso al de la reina Violante y al del infante don Manuel, unas 710 tahúllas: 470 en Cudiaçibir; 50 en Adufa; 80 en Benitahas; 110 en Alfarellas (Libro del Repartimiento de Murcia, f. 1, 3, 4, 6, 8, 10, 16). A esto debemos añadir en 1272, 26 tahúllas en Rabad Algidid. También recibió unas casa, probablemente de las mejores, situadas cerca de Santa María, con hornos, baños y tiendas que a su muerte fueron entregadas a don García Martínez para que sirvieran de morada a los obispos de Cartagena y que luego utilizaran los prelados de Murcia.

Por su categoría no es nada extraño que tubiera servidores como el caso de Zulemán Catorce, su almojarife; Pedro Martínez; Martín Jiménez (caballero); García Pérez, todos ellos beneficiados por privilegios.

Su fallecimiento tendría lugar ente finales de 1272 o inicios de 1273. (J. TORRES FONTES, Vid. nota 7).

15 Quizás esta diferencia de las cifras se deban a que D. MENJOT establece un total de 322 pobladores indeterminados frente al $17 \%$ dado por LACARRA, entre los que, tras un estudio exhaustivo, es probable identificar a algún navarro. Para este último autor, los navarros estarían dentro del grupo que clasifica como «otros» que suponen un $2 \%$ (68) y que Denis Menjot eleva a 4,1\%.

Sin embargo, y a pesar de las disgresiones, los libros de Repartimiento se convierte en una fuente de inestimable valor demográfico, incluso superior a los documentos fiscales o catastros, pues el número de propietarios, de los cuales nos revela sus nombres, responde de manera exacta al número de jefes de familias cristianas del reino. (D. MENJOT. vid. nota 7). 
dición socio-militar, son todos peones (medianos y menores ${ }^{16}$ ), salvo Domingo Navarro que recibe un mayor número de alfabas ${ }^{17}$.

Los peones menores reciben parte de sus pequeñas propiedades en la cuadrilla de Cotillas ${ }^{18}$ : Pascual Navarro y Bartolomé Navarro ${ }^{19}$ y Pedro Navarro ${ }^{20}$ quién es declarado ausente ya en 1266 como también se presupone para Juan Pérez Navarro ${ }^{21}$ pues su heredad la compra en estas fechas el caballero mediano Berenguer de Altariba. La palabra «ausente», tan frecuente en las particiones murcianas es reflejo de ese comportamiento social tan extendido de abandono de las nuevas tierras, ya fuese por ser zona de inseguridad o por no satisfacer las expectativas económicas del recién llegado, y que se convierte en un grave problema, pues la atracción primera de nuevos pobladores era sencilla, lo que realmente resultaba difícil era su permanencia, a pesar de existir la obligación a poblar la tierra un mínimo de cinco años y no poder vender ni enajenar su propiedad. Para ello veremos que Alfonso $X$ en su política repobladora recurre al amejoramiento de los lotes primitivos en los diferentes repartos.

En segundo lugar nos encontramos ante una serie de individuos inscritos en el Libro con su nombre seguido de un topónimo de origen más preciso. Son un total de veinte, entre los que destaca por su condición social y su papel político el ya nombrado Don Gil García de Azagra (vid. nota 14).

Si tomamos como punto de partida la ribera tudelana se observa una mayoritaria procedencia de gentes de este espacio: del propio núcleo de Tudela provienen los

16 Los peones menores recibían una alfaba y seis ochavas en esta partición; y los medianos una alfaba y media. Entre estos últimos encontramos dos personajes Lope Navarro (peón mediano) y Lope Navarro de Alcalá (peón menor). Este segundo presenta un doble topónimo quizás con la finalidad de diferenciarse del anterior. Pues ambos reciben tierras en la misma cuadrilla. Billora, o bien indicaba su último lugar de procedencia. En esta misma cuadrilla encontramos un poblador probablemente navarro, Pedro Navarret. Libro de repartimiento de Murcia, de TORRES FONTES, Murcia, 1991 (que se abreviará como $L R M$ ) f. 63.

17 Domingo Navarro, LRM f. 64.

Tahúlla es la medida de superficie para toda la tierra de riego, equivale a $1 / 6$ de una fanega o a $1 / 9$ de una hectárea. Una tahúlla son cuatro cuartas u ocho ochavas; la alfaba es una medida de valoración por tanto variable según la tierra. En general en tierra de albar equivale a ocho tahúllas (J. TORRES FONTES, vid. nota 7 ).

18 Se localiza en el actual azarbe de Cutillas, dependiente de la acequia menor de Alquibla de Mediodía. Aquí se formo una cuadrilla que destaca dentro del repartimiento por ser muy numerosa y por la variedad de oficios de sus componentes, que son en su mayoría menestrales y peones. Sus tierras no eran de gran calidad y se distribuyen entre un total de 233 pobladores. (J. TORRES FONTES, vid. nota 7).

Podemos hablar de una "concentración» de navarros que reciben parte de sus heredamiento en esta cuadrilla, un total de seis. Este agrupamiento de gentes de un mismo lugar de origen aceleraría el proceso de afianzamiento de la población, pues sería más rápido el proceso de creación de lazos de vecindad y originando grupos compactos de colonos, e incluso es probable sirvieran de foco de atracción de gentes de sus lugares de origen, pero sobre todo eran garantía de cierta estabilidad del poblamiento en una sociedad de gentes nuevas.

19 LRM f. 40.

20 LRM f. 41.

21 LRM f. 50. 
peones: Aemar de Tudela ${ }^{22}$ y Domingo Tudela ${ }^{23}$; de esta comarca son también originarios Martín Fernández de Fitero ${ }^{24}$, Pedro Ruiz de Corella ${ }^{25}$ y Gonzalo de Corella ${ }^{26}$, personajes de mayor rango militar y elevada condición social. Continuando con los pobladores procedentes de las tierras bañadas por el Ebro, contabilizamos la presencia, que podemos calificar como numerosa en relación al porcentaje global, de cuatro cabezas de familia, cuyo municipio de origen era Caparroso ${ }^{27} y$ tres del municipio vecino de Peralta ${ }^{28}$.

Estas gentes nos permiten dibujar claramente la dirección de un flujo migratorio que desde las tierras de la ribera, es decir la zona más meridional de Navarra, que recoje los elementos demográficos deseosos de emprender esa aventura que era la repoblación, pasan a la Rioja y descienden siguiendo la vertebración del sistema lbérico hacia las tierras del Levante. Gentes en su mayoría de dedicación agrícola que se adaptan a unos nuevos campos que se presentaban a sus ojos como de una gran riqueza, es la huerta murciana.

De los rebordes occidentales de la "Navarra nuclear", se certifica la presencia de dos pobladores procedentes del burgo de Estella, quizás burgueses francos de los cuales se señala en la documentación su oficio (cuchillero y blanquero) y que nos permite diferenciarlos pues ambos tienen el mismo nombre: Pedro Guillén de Estella ${ }^{29}$. Así como del valle de la Solana, es el caso de García Martínez de la Solana ${ }^{30}$.

22 LRM f. 50.

23 LRM f. 39.

24 Martín como peón menor recibe una alfaba y seis ochavas en la cuadrilla de Cuiaçibit, pero luego logra incrementar sus lotes con las tres alfabas y cinco ochavas que posee en Cotillas. $L R M$ f. 8,33 .

25 Recibe un donadío en la tercera partición con valor de 58 alfabas (107 tahúllas) LRM f. I,2,9. Aparece como testigo en documentos de la quinta partición, lo cual indica su continuidad de poblamiento, ( $L R M$ f. 90,94, 96) y en esta misma fecha, 1272 , el rey le da en heredamiento un casar de molinos en la acequia de Aquibla, seguramente en pago a sus servicios.

26 Gonzalo de Corella es caballero mayor y aparece como cuadrillero de Benetucer y Benifiar, sus posesiones tiene el valor de 19 alfabas y 6 ochavas (LRM f. 20, 22), también permanece como poblador "estable» pues recibe tierras en el reparto del Campo de Cartagena (LRM f. 98). La concesión de nuevas tierras era posible al existir tanto tierras abandonadas por los "ausentes» como las que las fuentes llaman «tierras vagadas» propiedades de antiguos propietarios musulmanes que emigraron sobre todo a partir 1266 al reino nazarita o hacia el norte de África.

27 Sancho de Caparroso. Carpintero ( $L R M$ f. 70); los peones medianos Pedro Serrano de Caparroso (LRM f. 63) y Pascual de Caparroso (LRM f. 63, 91), vecino este último, del labrador Don Martín de Caparroso en la collación de Santa María (LRM f. 91).

28 Son caballeros beneficiados en la tercera partición: Gil de Peralta (LRM f. 11, 26, 98) y Domingo Pérez de Peralta ( $L R M$ f. 28). Y en la quinta partición el teniente del maestre don Ramón, Jimén García de Peralta (LRM f. 84, 85, 99).

29 Ambos reciben tierras en la cuadrilla de Cotilla, que como ya hemos dicho más arriba se caracterizaba por el gran número de menestrales que la componían lo cual nos permite estudiar la dedicación profesional de estos primeros pobladores tanto en sus lugares de origen como en los de destino. Individuos necesarios para satisfacer las necesidades de una nueva población. ( $L R M$ f. 35, 35, 38, 45).

30 Heredero por compra et non fueron escriptos en padron, que posee unas once alfabas y media. (LRM f. 23). 
Por último de la fachada oriental de Pamplona, de donde es originario Martín Sánchez de Pamplona probablemente uno de los primeros pobladores pues es declarado ausente en $1266^{31}$, encontramos emigrantes de orígenes más dispersos: Ínigo de Aibar, quien formaría parte de esos primigenios repobladores que abandonaron las tierras que les fueron dadas, ya fuese para volver a su lugar de origen, o lo que resulta más probable, debido a la gran distancia que los separaba de su municipio, para dirigirse más hacia el sur, hacia las tierras andaluzas que también demandaban población, pues en 1266 el texto dice en la absencia de Yennego d'Ayvar...32; ausente en 1272 es declarado Juan López Eslava ${ }^{33}$; y por último del extremo nororiental de las tierras navarras, del valle del Roncal, procede Domingo Sancho Roncalés ${ }^{34}$.

Frente a este grupo de pobladores de origen navarro fácilmente identificables, hay nombres que por ser muy comunes no permiten una identificación precisa. Tal puede ser el caso de Íñigo Jiménez de Lorca y Juan López de Lorca ${ }^{35}$. O bien el de Domingo Monteagudo, peón menor, que junto a su mujer e hijos se ve beneficiado con tierras en la tercera partición ${ }^{36}$.

En el caso que el poblador no aparezca registrado por su apellido topónimo debemos acudir para su posible identificación, al patronímico, formado por el nombre del padre (patrilinealidad ${ }^{37}$ ) más los sufijos -ez, -aiz, -oz, -iz. Sirven quizás como ejemplos más significativos los casos de Î́nigue $z^{38}$.

31 LRM f. 45, 46.

32 LRM f. 50, 51, 54.

33 LRM f. 47, 88. Este personaje recibe en 1266 un donadío de casa de la reina en Benicotó de 30 alfabas y una y media en huerto. Esta heredad de Benicotó fue entregada casi en su totalidad en concepto de donadío a los servidores de la casa de la reina doña Violante. (J. TORRES FONTES, vid. nota 7$)$.

34 LRM f. 62, peón mayor que recibe las tierras de su heredamiento en la cuadrilla de Benivivas, que se caracteriza por asignarle a todos los pobladores una cantidad mayor de tierra arbolada y otra menor de albar. (J. TORRES FONTES, vid. nota 7).

35 El primero de ellos resulta ser una importante figura en la vida política-religiosa de Murcia hacia el año 1300 , debido a la resolución de pleitos con el obispo y el cabildo de la ciudad. LRM f. 64 y $L R M$ f. 85. Ambos individuos pueden proceder de la vecina Lorca, villa del reino de Murcia que por su carácter fronterizo con el reino granadino no presentaba unas condiciones de vida muy favorables por tanto es una hipótesis bastante probable, o bien del municipio de Lorca en el valle de la Solana, pues el nombre de Íñigo resulta ser un indicativo importante.

36 Este personaje y su familia puede ser originario del municipio de la zona más meridional del reino navarro, colindante con Aragón, o por el contrario del municipio próximo a Murcia, cerro donde existía una importante fortaleza defensiva desde 1078 y que en 1268 pertenecía al donadío de doña Violante con sus viñas y secano.

37 La tendencia a la patrilinealidad del apellido, es decir a recibir el apellido del padre, se debe a la influencia los grupos repobladores castellanos-leoneses. Estos individuos conservan su identidad (referencia a un espacio) y aún más, la refuerzan. Esta práctica cada vez más general de una filiación más personal frente a la espacial y patrifilial más que matrilineal, consecuencia de la influencia castellana, se constata en la edad Moderna en el solar navarro. (A. ZABALZA y A. MORENO, Identidad social y espacio en la Navarra Pirenaica, Pamplona, 1996).

38 Jimeno íñiguez, LRM f. 55; Pedro Íñiguez, LRM f. 26; María Îniguez, LRM f. 6; Martín Íñiguez, LRM f. 97. 
En último lugar haremos referencias a estos beneficiados de los repartimientos de tierras en el reino murciano cuyos nombres son de clara tradición navarra: Íñigo ${ }^{39}$, Velasco (Blasco $)^{40}$ o Fortún ${ }^{41}$. Ejemplos todos muy significativos pero que no permiten el realizár una afirmación rigurosa sin riesgo a equivocarnos, pues la difusión de los nombres en estos siglos bajomedievales era práctica frecuente. De este modo encontramos individuos cuyo nombre es de claro origen catalán, Guillén seguido de uno navarro, Fortún (LRM f. 61, 95).

El grupo de estos últimos que presentan mayor dificultad a la hora de precisar su procedencia geográfica son un total de doce que elevaría la suma global de pobladores navarros a treinta y nueve, aunque volvemos a señalar que los últimos presentan un margen de duda.

\subsection{Vascos}

Hasta aquí nos hemos ocupado de los navarros que las fuentes nos permiten identificar como nuevos pobladores en el solar murciano, pasando ahora a aquellos que llegaban de las tierras vascas. Su número es claramente inferior, debido tanto a que su lugar de origen está más alejado y cuyas condiciones geográficas, un territorio de pequeñas dimensiones de carácter montañoso, se presentan menos favorables para la movilización de su población. Ésta puede ser la razón de que el protagonismo de los vascos en la repoblación murciana quede asumido de manera mayoritaria por los alaveses, los más próximos y con fácil acceso a Castilla.

En primer lugar analizaremos aquellos individuos de los que podemos determinar su origen gracias a que su nombre aparece junto a un apellido topónimo de un municipio alavés, no todos ellos son repobladores tal como veremos: Heredia ${ }^{42}$; Ayala $^{43}$; San Román ${ }^{44}$;

39 Íñigo López, LRM f. 55 y 98.

40 Velasco Pérez, LRM t. 88; Blasco Pérez, LRM f. 47.

41 Fortún Sánchez, LRM f. 68, 71, 73, 86, 88, 90, 92, 94, 98. Alcalde de Murcia que participa en el reparto de la heredad de Aquibla en la quinta partición, o en el Campo de Cartagena, y en los términos de Benieça y Benibarrira. Poseía un total de 26 alfabas repartidas en diferentes cuadrillas.

Fortún López, LRM $f 83$ y 84 que recibe un total de 20 alfabas.

42 Los caballeros menores: Juan López de Heredia ( $L R M$ f. 56) y Juan Pérez de Heredia (LRMf. 58). Por último Ruy Jiménez de Heredia que recibió en la tercera partición un heredamiento por valor de 20 alfabas, pero que es declarado ausente en 1272 y sus tierras entregadas a Ponce de Villanueva. (LRM f. 20,88).

43 Martín López de Ayala (LRM f. 10).

O Pedro López de Ayala quien no aparece citado en el Libro de Rapartimiento, pero que merece ser destacado pues fue Adelantado Mayor del reino de Murcia durante el reinado de Alfonso XI hasta el año 1325. Este personaje, miembro del linaje nobiliario alavés de Ayala, es abuelo del gran canciller escritor. J. TORRES FONTES El concejo de Murcia en el reinado de Alfonso XI.

44 Pedro López de San Román, peón menor que acude con su mujer e hijos, recibe en la tercera partición tierras en la sierra de Tiñosa, sin regadío y otras de riego en la misma cuadrilla. (LRM f. 64). 
Mendoza $^{45}$; La Guardia ${ }^{46}$ y por último aunque no aparece recogido en el Libro de Repartimiento, pero si fue un beneficiado de los repartos de las tierras de este reino y probablemente poblador, Pedro López de Álava ${ }^{47}$.

En segundo lugar nos encontramos en las fuentes con personajes denominados con un nombre seguido de patronímicos que se han convertido en apellidos de claras referencias alavesas: es el caso de Domingo Hurtado ${ }^{48}$; Ladrón ${ }^{49}$, caballero mayor y vasallo del infante don Manuel que recibe tierras por valor de 20 alfabas en las cuadriIlas de Alfatella y Algualega. Este personaje es objeto de un proceso, pues en 1272 se le declara ausente, mientras él alega lo contrario Ladron dixo que los jurados no le devieran fazer absente porque touo et tenia aqui cauallo et armas suyo; o bien la viuda madre de Ferrán Ladrón ${ }^{50}$.

Estos tres últimos pobladores junto a los seis anteriores, citados en el Libro de Repartimiento, indican la escasa participación de vascos en la repoblación de esta tierra de un gran atractivo agrícola, pero a gran distancia. Además las condiciones física de esta región montañosa no presentaban una salida fácil hacia el exterior, de ahi que el porcentaje absoluto correspondan a gentes de la llanura alavesa que desde 1100 a 1300 experimenta un importante crecimiento demográfico.

\section{CONSIDERACIONES FINALES}

El incremento demográfico de la población navarra y de las tierras meridionales vascas, que culmina en el siglo XIII, perfectamente documentado, contribuye a la explicación de la presencia de vascos y navarros en las costas del Levante. Ya desde comienzos del siglo XII, estos efectivos demográficos se dirigen hacia las zonas ganadas al Islam (ej. Tudela 1119). De este modo, el valle del Ebro, los cursos inferiores del Arga, Aragón y Ega se convierten en ricas tierras receptoras de emigrantes procedentes del norte. Hasta aquí, se cierra una primera etapa, iniciándose una segunda con

45 Lope de Mendoza, su carácter de poblador parece ponerse en duda pues no aparece como beneficiado de los repartos, las únicas noticias que tenemos sobre él son a raíz de un peito a un tal Ladrón. En 1272 Lope, quizás miembro del linaje nobiliario de los Mendoza, junto con sus hombres y otros caballeros está unos días en casa de Ladrón, vecino de la collación de Santa María, quizás se dirigían hacia otro punto más al sur y aprovechan la hospitalidad de este poblador oriundo de su tierra.

46 Municipio cuyo nombre es bastante común, lo cual no nos permite una determinación clara sobre el origen del poblador, aunque en este caso por una parte el hecho de la proximidad a las tierras castellanas del municipio a través de Laguardia como por otra el nombre de Sancho pueden ayudarnos a establecer un posible origen en las tierras vasco-navarras: Sancho Ruiz de la Guardia, peón menor de la cuadrilla de Cudiaçibit (LRM f. 8).

47 En 1266 este almotacén de Alfonso $X$ recibe de manos reales un rafal en la pendiente de Mendigol, con una situación muy favorable al hallarse en la desembocadura de la rambia o cañada que recogía las aguas de la sierra del Puerto.

48 En 1266 recibe un heredamiento de tres alfabas y cuarto en las cuadrillas de la $V$ Alquería y Benicomay. (LRM f. 51).

49 LRM f. 57, 88, 91, 95.

50 LRM f. 65, 66, 94. 
las corrientes de emigración hacia el sur, hacia las tierras que desde 1212 se incorporan a los dominios cristianos, Andalucía y Levante.

En este último caso, la presencia de pobladores navarros en Murcia pueda estar en relación con una segunda oleda de migraciones procedente del reino valenciano. No cabe duda que el Levante fuese un segundo punto de inflexión del despliegue de población fuera de los límites navarros. La adaptación y permanencia de estos primeros pobladores no sólo aseguraba la repoblación sino que facilitaba la llegada de muchos más de su mismo lugar de procedencia geográfica. Ya que el asentamiento de algunos y la seguridad cara al futuro servían de llamadas a sus vecinos del lugar de origen.

Próximos estudios sistemáticos y detallados de los libros de Repartimiento de tieras de los municipios de Lorca y Orihuela nos permitirán comprobar y afirmar de nuevo que el reino de Murcia fue receptor del segundo gran salto de la población navarra y vasca que tomando como eje el conjunto orográfico del Sistema Ibérico afluyen directamente o desde escalas intermedias a estas latitudes peninsulares. 